\title{
Perencanaan desain reaktor biodiesel sistem batch untuk produksi biodiesel skala industri kecil
}

\author{
Shofiatul Ula ${ }^{*}$, Fadwah Maghfurah ${ }^{2}$, Syarif Abdullah ${ }^{3}$, Aditiyo Hermawan $\mathrm{K}^{4}$ \\ Program Studi Teknik Mesin, Fakultas Teknik, Universitas Muhammadiyah Tasikmalaya ${ }^{1,4}$ \\ Jl. Tamansari Km 2,5 Kota Tasikmalaya 46196 \\ Jurusan Teknik Mesin, Fakultas Teknik, Universitas Muhammadiyah Jakarta² \\ Jl. Cempaka Putih Tengah No. 27, Jakarta Pusat 10510 \\ Jurusan Teknik Mesin, Fakultas Teknik, Universitas Sultan Ageng Tirtayasa ${ }^{3}$ \\ Jl. Jendral Sudirman Km. 3, Kota Cilegon \\ *Corresponding author: shofiatulula@yahoo.com
}

\begin{abstract}
Recently biodiesel production is produced by large industries. In order to be produced by small industries, the biodiesel production process requires good design which will affect the cost and yield of production. This research aims to make a batch system biodiesel reactor design and find out what materials are used in order to produce small-scale industrial biodiesel. This research is expected to provide small-scale industrial biodiesel production opportunities and the industry able to produce fuel independently. The batch system biodiesel reactor that has been designed production capacity of 144 liters each day. It has the following specifications: consists of 2 volume tubes each of which 38.2 liters with stainless steel material and 2 volume tubes of 38.2 liters each with plastic material HDPE motor power is $260 \mathrm{Kw}$, shaft diameter $20 \mathrm{~mm}$, pulley length $134 \mathrm{~cm}$ using type A, the stirring process uses bevel gear, and the type of gear used is cold dipped steel and S45C steel material.
\end{abstract}

Keywords: design reactor, biodiesel, batch system, small-scale industry

\begin{abstract}
Abstrak
Pada saat ini produksi biodiesel diproduksi oleh industri besar. Agar dapat diproduksi oleh industri kecil proses produksi biodiesel memerlukan perancangan yang baik dari desain hingga material yang akan digunakan yang akan berpengaruh terhadap biaya dan hasil produksi. Penelitian ini bertujuan untuk membuat desain reaktor biodiesel sistem batch dan mengetahui material apa saja yang digunakan agar dapat memproduksi biodiesel skala industri kecil. Penelitian ini diharapkan dapat memberikan manfaat sebagai peluang usaha produksi biodiesel skala industri kecil, memberikan masukan kepada industri agar bisa memproduksi bahan bakar secara mandiri. Reaktor biodiesel sistem batch yang telah didesain memiliki kapasitas produksi 144 liter per hari memiliki spesifikasi berikut: terdiri dari 2 tabung volume masing-masing adalah 38,2 liter dengan material Stainless Steel dan 2 tabung volume masingmasing adalah 38,2 liter dengan material plastik HDPE daya motor adalah $260 \mathrm{Kw}$, diameter poros $20 \mathrm{~mm}$, panjang puli $134 \mathrm{~cm}$ menggunakan tipe A, proses pengadukan menggunakan bevel gear, dan jenis roda gigi yang digunakan adalah bahan $\mathrm{S} 45 \mathrm{C}$ baja dicelup dingin dan temper.
\end{abstract}

Kata kunci: desain reaktor, biodiesel, sistem batch, industri kecil.

\section{Pendahuluan}

Solar merupakan salah satu jenis bahan bakar yang dihasilkan dari proses pengolahan minyak bumi. Bahan bakar dari minyak bumi apabila dikonsumsi secara terus menerus lama-lama akan habis.
Kebutuhan akan bahan bakar solar semakin meningkat, diantaranya untuk rumah tangga, transportasi atau industri.

Berdasarkan Handbook Of Energy \& Economics Statistics Of Indonesia, salah satu konsumsi energi nasional terbanyak 
berasal dari sektor industri, yaitu membutuhkan 360.538 juta Barel Oil Equivalent (BOE). Kebutuhan energi nasional 74 persen tergantung kepada minyak bumi. Pemerintah sendiri telah mengumumkan rencana untuk mengurangi ketergantungan Indonesia dengan mengeluarkan Peraturan Presiden Indonesia Nomor 5 Tahun 2006 tentang Kebijakan Energi Nasional untuk mengembangkan sumber energy [10]. Untuk pengembangan sumber energi tersebut maka penelitian mengenai bahan bakar alternatif pengganti bahan bakar yang bersumber dari minyak bumi terus dilakukan, salah satunya adalah penelitian mengenai biodiesel.

Biodiesel merupakan bahan bakar pengganti solar yang berasal dari bahan baku nabati [1]. Bahan baku nabati tersebut dapat berasal dari minyak kelapa, kelapa sawit, jarak, ataupun minyak jelantah. Kelebihan biodiesel dibandingkan solar adalah biodiesel lebih ramah lingkungan. Biodiesel sudah mulai diproduksi dan dipasarkan di Indonesia.

Pada saat ini produksi biodiesel di Indonesia diproduksi oleh industri besar, bahan baku yang digunakan berasal dari kelapa sawit. Perusahaan yang memproduksi biodiesel di antaranya adalah PT. Cemerlang Energi Perkasa (83.441 kl), PT. Wilmar Bioenergi Indonesia (192.000 kl), PT. Pelita Agung Agrindustri (27.814 kl), PT Ciliandra Perkasa (34.767 kl), dan PT Musim Mas (160.300 kl) [3].

Terdapat 3 jenis teknologi untuk memproduksi biodiesel, yaitu pirolisis, mikroemulsifikasi, dan transesterifikasi. Pada saat ini sebutan biodiesel berarti bidiesel yang diproses dengan metode transesterifikasi, yaitu reaksi kimia antara trigliserida dengan alcohol rendah yang menghasilkan gliserida dan ester asam lemak [7].

Proses transesterifikasi terjadi di dalam suatu reaktor. Reaktor merupakan tempat di mana suatu reaksi berlangsung. Dalam pemilihan reaktor oleh suatu industri, terdapat faktor-faktor yang menjadi bahan pertimbangan, di antaranya mendapat keuntungan yang besar, biaya produksi rendah, modal kecil/volume reaktor minimum, operasinya sederhana dan murah, eselamatan kerja terjamin, serta polusi terhadap sekelilingnya (lingkungan) dijaga sekecil-kecilnya.

Pada proses produksi biodiesel terdapat parameter-parameter yang mempengaruhi proses biodiesel, yaitu kadar air, asam lemak bebas, rasio alkohol dengan minyak, pemilihan katalisator, konsentrasi, kondisi suhu, tekanan reaksi, proses batch atau proses kontinyu. Proses batch sangat baik untuk produksi biodiesel skala industri kecil [7].

Tujuan dari penelitian ini adalah membuat perencanaan desain reaktor sistem batch untuk produksi biodiesel skala industri kecil sehingga diketahui spesifikasi dan gambar desain reaktor tersebut.

\section{Tinjauan Pustaka}

Biodiesel adalah bahan bakar yang terdiri dari campuran mono-alkil ester dari rantai panjang asam lemak, yang dipakai sebagai alternatif bagi bahan bakar dari mesin diesel. Biodiesel dibuat dari minyak nabati, baik minyak baru maupun bekas penggorengan melalui proses transesterifikasi, esterifikasi, atau proses esterifikasi-transesterifikasi [1].

Menurut hasil riset Badan Pengkajian

dan Penerapan Teknologi (BPPT), Indonesia memiliki banyak jenis tanaman yang berpotensi menjadi sumber bahan bakar alternatif, biodiesel dapat diperoleh dari kelapa sawit, kelapa, jarak pagar, sirsak, srikaya, dan kapuk [8].

Bahan pangan sebaiknya tidak dibuat biodiesel mengingat di Indonesia ketersediaan pangan masih belum sepenuhnya terpenuhi. Penggunaan bahan baku non pangan akan mengurangi biaya produksi pembuatannya. Bahan baku non pangan untuk pembuatan biodiesel di antaranya adalah jarak (castor), minyak jatropha curcas atau physic nut, minyak biji karet, minyak biji tembakau, dan Limbah minyak goring atau jelantah, harganya 
murah dan tidak menyebabkan pencemaran lingkungan [7].

Pemanfaatan minyak nabati sebagai bahan baku biodiesel memiliki beberapa kelebihan diantaranya sumber minyak nabati mudah diperoleh, pembuatan biodiesel dari minyak nabati mudah dan cepat, dan tingkat konversi minyak nabati menjadi biodiesel tinggi (mencapai 95\%) [1].

Proses pembuatan biodiesel sangat sederhana. Biodiesel dihasilkan melalui proses transesterifikasi minyak atau lemak dengan alkohol. Alkohol akan menggantikan gugus alcohol pada struktur ester minyak dengan dibantu katalis. $\mathrm{NaOH}$ dan $\mathrm{KOH}$ adalah katalis yang umum digunakan. Proses transesterifikasi bertujuan untuk menurunkan viskositas (kekentalan) minyak, sehingga mendekati viskositas solar [1].

Penelitian mengenai proses pembuatan biodiesl telah banyak dilakukan. Penelitian lebih fokus pada bagaimana menghasilkan biodiesel yang berkualitas. Evy Setiawati dan Fatmir Edwar pada tahun 2012 telah melakukan penelitian mengenai pengolahan minyak jelantah dengan metode mikrofiltrasi dan transesterifikasi. Hasil penelitiannya menunjukkan bahwa teknologi mikrofiltrasi dapat digunakan untuk meningkatkan kualitas minyak jelantah, yaitu berupa penurunan kadar asam lemak bebas sebesar 13\%-72\% [5].

Biodiesel yang dipasarkan masih merupakan campuran biodiesel dan solar. Dalam istilah perdagangan, biodiesel yang dicampurkan dalam minyak solar dinyatakan dalam notasi B-XX. Misalnya, B-10 menunjukkan campuran bahan bakar tersebut mengandung 10\%-volume biodiesel dan 90\%-volume minyak solar [4]. Reaktor adalah adalah suatu alat proses tempat di mana terjadinya suatu reaksi berlangsung, baik itu reaksi kimia atau nuklir dan bukan secara fisika. Berdasarkan prosesnya reaktor dibagi menjadi 3 jenis, yaitu :

1. Reaktor batch, reaktor ini memiliki pengaduk yang berisi reaktan, tidak ada aliran inlet atau outlet selama operasi. Reaktor jenis ini biasanya sangat cocok digunakan untuk produksi berkapasitas kecil misalnya dalam proses pelarutan padatan, pencampuran produk, reaksi kimia, Batch distillation, kristalisasi, ekstraksi cair-cair, polimerisasi, farmasi dan fermentasi.

2. Reaktor semi batch, biasanya berbentuk tangki yang berpengaduk. Cara operasinya dengan jalan memasukkan sebagian zat pereaksi ke dalam reaktor, sedangkan zat pereaksi yang lain atau sisanya dimasukkan secara kontinu ke dalam reaktor. Ada material masuk selama operasi tanpa dipindahkan, reaktan (massa) yang masuk bisa dihentikan dan produk bisa dipindahkan selama operasi waktu tertentu, serta tidak beroperasi secara steady state.

3. Proses kontinyu (reaktor pipa, reaktor tanki). Reaktor ini mempunyai aliran masukan dan keluaran (inlet/outlet) yang terdiri dari campuran homogen/ heterogen. Reaksi kontinue di operasikan pada kondisi steady. Dimana arus aliran masuk sama dengan arus aliran keluar.

Pemilihan reaktor disesuaikan dengan kebutuhan produksi, tujuan pemilihan reaktor tersebut adalah untuk endapat keuntungan yang besar, biaya produksi rendah, modal kecil/volume reaktor minimum, operasinya sederhana dan murah, keselamatan kerja terjamin, dan polusi terhadap sekelilingnya (lingkungan) dijaga sekecil-kecilnya

Pemilihan jenis reaktor dipengaruhi oleh fase zat pereaksi dan hasil reaksi, tipe reaksi dan persamaan kecepatan reaksi, serta ada tidaknya reaksi samping, kapasitas produksi, harga alat (reaktor) dan biaya instalasinya dan kemampuan reaktor untuk menyediakan luas permukaan yang cukup untuk perpindahan panas.

Harga solar pada saat ini mengalami turun naik. Harga solar masih disubsidi oleh pemerintah. Biodiesel merupakan bahan bakar pengganti solar. Dengan adanya mandatori biodiesel yang tertuang dalam Peraturan Menteri ESDM No. 20/2014 yang 
mewajibkan kadar biodiesel 20\% (B20) pada 2016 maka produksi biodiesel di Indonesia terus dilakukan.

Tabel 1. Pentahapan Kewajiban Minimal Pemanfaatan Biodiesel (B100) Sebagai Campuran Minyak

\begin{tabular}{lcccc}
\hline \multicolumn{1}{c}{ Jenis Sektor } & $\begin{array}{c}\text { April } \\
2015\end{array}$ & $\begin{array}{c}\text { Januari } \\
2016\end{array}$ & $\begin{array}{c}\text { Januari } \\
2020\end{array}$ & $\begin{array}{c}\text { Januari } \\
2025\end{array}$ \\
\hline Rumah Tangga & - & - & - & - \\
\hline $\begin{array}{l}\text { Udsaha Mikro, } \\
\text { Usaha Perkanan, }\end{array}$ & $15 \%$ & $20 \%$ & $30 \%$ & $30 \%$ \\
$\begin{array}{l}\text { Usaha Pertanian, } \\
\text { Transporta-si, dan } \\
\text { Pelayanan Umum } \\
\text { (PSO) }\end{array}$ & & & & \\
\hline Industri Non PSO & $15 \%$ & $20 \%$ & $30 \%$ & $30 \%$ \\
\hline $\begin{array}{l}\text { Industri dan } \\
\text { Komersial }\end{array}$ & $15 \%$ & $20 \%$ & $30 \%$ & $30 \%$ \\
\hline $\begin{array}{l}\text { Pembangkit } \\
\text { Listrik }\end{array}$ & $25 \%$ & $30 \%$ & $30 \%$ & $30 \%$ \\
\hline
\end{tabular}

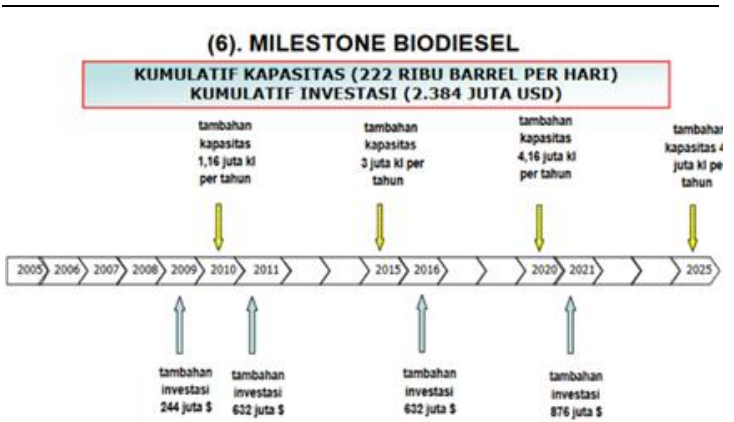

Gambar 1. Milestone Biodiesel di Indonesia

Penelitian mengenai produksi biodiesel terus dilakukan, hasil penelitian Tri Yuni Hendrawati [2] menunjukkan bahan baku biodiesel yang potensial berdasarkan prioritas terbaik di tingkat nasional adalah kelapa sawit. Hasil analisis teknoekonomi layak ari sisi kelayakan finansial pada kapasitas produksi biodiesel sawit sebesar 100.000 ton/tahun atau 300 ton/hari. Dengan tingkat konversi 98\%, jumlah CPO yang dibutuhkan oleh pabrik ini adalah sebanyak 102.041 ton/tahun atau 306 ton/hari.

Toniaga yang berasal dari Bogor, tepatnya di Jonggol merupakan salah satu daerah yang mulai memproduksi biodiesel dari minyak jelantah. Untuk membuat biodiesel dari minyak jelantah ini relatif mudah. Biaya produksinya hanya Rp 2.000 per liter. Toniaga dapat mengambil keuntungan sekitar Rp 2.750 per liter.

Hasil penelitian Shofiatul Ula [9] mengenai kelayakan produksi biodiesel dari minyak jelantah skala industry kecil menunjukkan bahwa biodiesel dari layak diproduksi oleh industri kecil dengan nilai Break Event Point (BEP) 3.367 liter/tahun, nilai kelayakan usaha (B/C ratio) 1.34, Return of Investment (ROI) $34.65 \%$, dan Pay Back Period (PBP) 2.46 tahun.

\section{Metode Penelitian}

Tahapan-tahapan penelitian ini dapat dilihat pada gambar 2 .

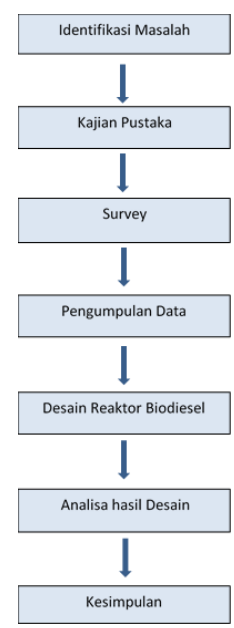

Gambar 2. Tahapan-tahapan penelitian

1. Identifikasi masalah

Penelitian ini dilatarbelakangi oleh kebutuhan akan solar yang meningkat, menurunnya cadangan minyak bumi, adanya Peraturan Menteri ESDM mengenai penggunaan biodiesel dan pada saat ini biodiesel diproduksi oleh industri besar. Produksi Biodiesel untuk industri kecil belum banyak dilakukan, efektivitas reaktor menjadi pertimbangan dalam produksi biodiesl skala industry kecil.

2. Kajian Pustaka

Mengkaji literatur-literatur mengenai produksi biodiesel.

3. Survey

Untuk mendukung teori yang telah dikaji, maka perlu dilakukan kunjungan/survey. Survey dilakukan 2 kali, yaitu ke Laboratorium SBRC di IPB Bogor dan ke PT. Bogor Energy Equatorial di Bogor.

4. Pengumpulan Data

Dari kajian-kajian pustaka dan hasil survey maka diperoleh data mengenai 
material dan bagian-bagian apa saja yang dibutuhkan untuk membuat reaktor biodiesel sistem batch serta perhitungan dimensi dan volume yang dibutuhkan.

5. Mendesain Reaktor Biodiesel

Setelah diketahui data-data yang dibutuhkan untuk mendesain reaktor biodiesel, maka dibuatlah desain biodiesel sistem batch mulai dari proses perlakuan terhadap bahan baku sampai diperoleh rendemen berupa biodiesel, material yang digunakan sehingga mendapatkan kapasistas reaktor unuk produksi biodiesel. Desain biodiesel menggunakan Solidwork 2015.

6. Analisa Hasil Desain

Desain yang dihasilkan dianalisa mengenai kesesuaian dengan material yang dibutuhkan dalam pembuatannya.

7. Kesimpulan

Desain reaktor biodiesel sistem batch apakah ada kelayakan untuk dibuat sehingga dapat digunakan oleh industri kecil untuk memproduksi biodiesel.

\section{Hasil dan Pembahasan}

Alat yang didesain adalah reaktor biodiesel sistem batch, karena sistem ini adalah yang cocok untuk kapasitas kecil.

a. Beban rangka

Beban rangka yang direncanakan adalah sebagai berikut:

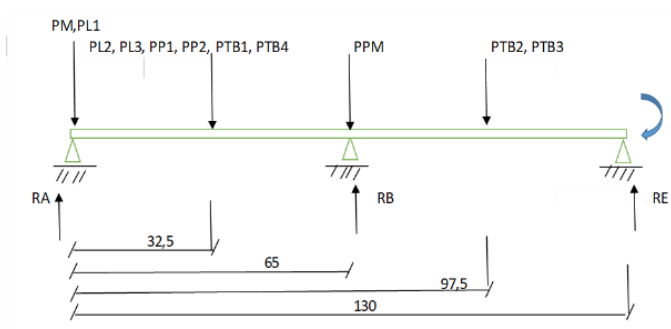

Gambar 3. Beban rangka tabung biodiesel

Keterangan:

$\mathrm{Pm}=$ Beban motor $=5 \mathrm{~kg}$

$\mathrm{PL}_{123}=$ Beban pully $123=1,0 \mathrm{~kg}$ dan 0,5

$\mathrm{kg}$

$\mathrm{PTB}_{1234}=$ Beban tabung ${ }_{1234}=38,20 \mathrm{~kg}$

$\mathrm{PP}_{12}=$ Beban Pengaduk $_{12}=2 \mathrm{~kg}$
$\mathrm{PPM}=$ Beban pompa $=5 \mathrm{~kg}$

Jarak $=$ satuan dalam centimeter $(\mathrm{cm})$

$\mathrm{RA}=48,43 \mathrm{~kg} . \mathrm{cm}$

$\mathrm{RB}=80,93 \mathrm{~kg} \cdot \mathrm{cm}$

$\mathrm{RE}=\mathrm{RE}=36,47 \mathrm{~kg} \cdot \mathrm{cm}$

b. Dimensi tabung

1. Tabung 1 Material Stainless Steel sebanyak 1 tabung, dalam perencanaan proses pengolahan biodieselnya berisi 25 Liter minyak nabati, 5 liter etanol, 0,266 liter $\mathrm{NaOH}$, dengan total volume 30,266 liter. Kapasitas tabung di tambah $25 \%$ sehingga menjadi 38,207 liter. Pada tabung terdapat thermokopel. Cycle time mixer selama 15 menit.

2. Tabung 2

Material Plastik HDPE sebanyak 8 tabung. Berisi sama dengan tabung ke-1 lalu diendapkan selama 24 jam. Kapasitas tabung di tambah 25\% sehingga menjadi 38,207 liter.

3. Tabung 3

Material Plastik HDPE sebanyak 1 tabung. Berisi sama dengan tabung ke-2 lalu di cuci dengan ditambahkan 2,5 liter asam cuka Serta 5 liter air selama 15 menit.

4. Tabung 4

Material Stainless steel sebanyak 1 tabung. Berisi sama dengan tabung ke-3 lalu di dihilangkan kadar airnya selama 15 menit dan hasilnya 17,5 liter. Kapasitas tabung di tambah $25 \%$ sehingga menjadi 38,207 liter.

Total output per-hari adalah 144 liter (8 jam produksi).

c. Transmisi

Dalam perancangan dan perhitungan kontruksi mesin reaktor biodiesel ini diperlukan penggerak utama motor listrik yang memenuhi spesifikasi, dimana daya rencana dan momen puntir pada poros harus dilakukan perhitungan diketahui daya motor $0,5 \mathrm{HP}=0,37 \mathrm{~kW}$ dan faktor koreksi ialah 1,3 Diambil berdasarkan penggunaan mesin 8-10 jam perhari [6]. Setelah dilakukan perhitungan, diperoleh: 
1. Kecepatan sinkron motor $=1330 \mathrm{rpm}$

2. Slip pada motor $=0$

3. Daya rencana $=0,481 \mathrm{~kW}$

4. Torsi yang dihasilkan $=1,97 \mathrm{Nm}$

5. Putaran motor per detik $=22,1 \mathrm{rps}$

6. Daya mekanik $=260 \mathrm{~kW}$

d. Poros

Daya dan putaran motor yang telah ditentukan dengan mempertimbangkan bahwa daya yang dibutuhkan tidak terlalu besar maka berdasarkan spesifikasi motor adalah sebagai berikut:

$\mathrm{P}=0,5 \mathrm{HP}=0,3675 \mathrm{~kW}$

$\mathrm{n}_{1}=1400 \mathrm{rpm}$

Hasil perhitungan dari perencanaan poros yang didapat adalah 16,123 $\mathrm{mm}$. Poros yang akan dipilih dalam rancang bangun ini, dengan yang ada di pasaran yaitu dengan menggunakan poros dengan berdiameter $20 \mathrm{~mm}$.

e. Pasak

Penampang pasak yang direncanakan menggunakan persamaan pada rumus, yaitu $6 \times 5(\mathrm{~mm})$. Bahan pasak yang digunakan adalah S45C.Tegangan geser yang diijinkan $=1,94$ $\mathrm{kg} /\left(\mathrm{mm}^{2}\right)=0,000019012 \mathrm{~N} / \mathrm{m}^{2}$.

Tekanan permukaan yang diizinkan pa $(\mathrm{kg} / \mathrm{mm} 2)$ di berikan sebesar $8 \mathrm{~kg} / \mathrm{mm} 2$ karena poros dengan ukuran berdiameter kecil. Dan untuk mengetahui keamanan pasak, akan dihitung dengan persamaan pada rumus sebagai berikut:

$\mathrm{b} / \mathrm{d}_{\mathrm{s}}=0,25<$ hasil $<0,35$

$6 / 20=0,3 ; 0,25<0,3<0,35$

Nilai 0,3 adalah nilai yang berada lebih besar dari 0,25 dan lebih kecil dari 0,35, maka hasilnya adalah aman.

f. Sabuk V

Jarak antar pusat puli diketahui $250 \mathrm{~mm}$. Jika dihitung melalui diameter luar belt dibutuhkan panjang belt $134 \mathrm{~cm}$. Puli yang digunakan ialah puli tipe-A maka sabuk-V yang digunakan juga menggunakan sabuk-V tipe-A.

Momen rencana $=1761,25 \mathrm{~kg} . \mathrm{mm}$

Kecepatan sabuk $=1,12 \mathrm{~m} / \mathrm{s}$

g. Bantalan (Bearing)
Hasil dari perhitungan perencanaan bantalan ini didapatkan hasil dengan panjang bantalan yaitu sebesar $10 \mathrm{~mm}$. Maka dari hasil panjang bantalan dan diameter poros yang digunakan maka dipilih menggunakan bantalan gelinding yang ada dipasaran dengan nomor bantalan $6204 \mathrm{zz}$ dengan diameter dalam $20 \mathrm{~mm}$, diameter luar $47 \mathrm{~mm}$ dan lebar 14 $\mathrm{mm}$.

Dari hasil perhitungan di atas, umur bantalan dapat memiliki masa pakai yang sangat baik yaitu 1.181.995 jam.

h. Bevel gear

1. Factor koreksi $=1,2$, daya rencana $=$ $0,441 \mathrm{~kW}$

2. Jumlah mata gigi yang digunakan pada roda gigi penggerak berjumlah 10 gigi dan 16 gigi pada roda gigi yang digerakkan, maka gear ratio $=$ 1,6 .

3. Sudut kerucut jarak bagi $=58^{\circ}$.

4. Diameter lingkaran jarak bagi:

$\mathrm{d}_{1}=137,79 \mathrm{~mm}$

$\mathrm{d}_{2}=220,50 \mathrm{~mm}$

5. Modul $=5,08 \mathrm{~mm}$.

6. Kecepatan keliling $=10,09 \mathrm{~m} / \mathrm{s}$.

7. Gaya tangensial $=43,798 \mathrm{~N}$.

8. Kelonggaran puncak didapat sebesar $\mathrm{ck}=0,25 \times 5,08=1,27 \mathrm{~mm}$.

9. Jenis roda gigi yang digunakan adalah bahan S45C baja dicelup dingin dan temper.

i. Mur dan baut

1. Menentukan besarnya beban maksimum yang diterima oleh masing masing baut dan mur. Dengan faktor koreksi $\mathrm{f}_{\mathrm{c}}=1,2-2.0$ maka faktor koreksi yang dipilih adalah $\mathrm{f}_{\mathrm{c}}=1,2$. Untuk perhitungan terhadap deformasi. Beban $\mathrm{W}$ yaitu diambil dari jumlah beban total komponen dan rangka sebesar 66,8 $\mathrm{kg}$ dimana melitputi wadah dan saringan.

$\mathrm{W}_{\max }=173,124 \mathrm{~kg}$.

2. Bahan baut dan mur yang direncanakan dari baja liat dengan kadar karbon $0,2 \% \mathrm{C}=\mathrm{ST}-34$.

3. Kekuatan Tarik $=41,25 \mathrm{~kg} / \mathrm{mm}$ 
4. Kekuatan geser $=20,625 \mathrm{~kg} / \mathrm{mm}$

j. Pengelasan bertujuan untuk menyambung-kan besi yang sudah dipotong sesuai ukuran. Pengelasan Teknik pengelasan yang digunakan adalah las busur listrik atau SMAW (Shield Metal Arc Welding). Pada proses ini digunakan elektroda dengan ukuran $\varnothing$ 3,2 X $350 \mathrm{~mm}$, dan spesifikasi E6013. Digunakan jenis las tersebut karena akan lebih mudah di lakukan dan hasil penyambungan cukup kuat.

Berdasarkan perhitungan di atas maka didesain reaktor sitem batch menggunakan solidwork 2015.

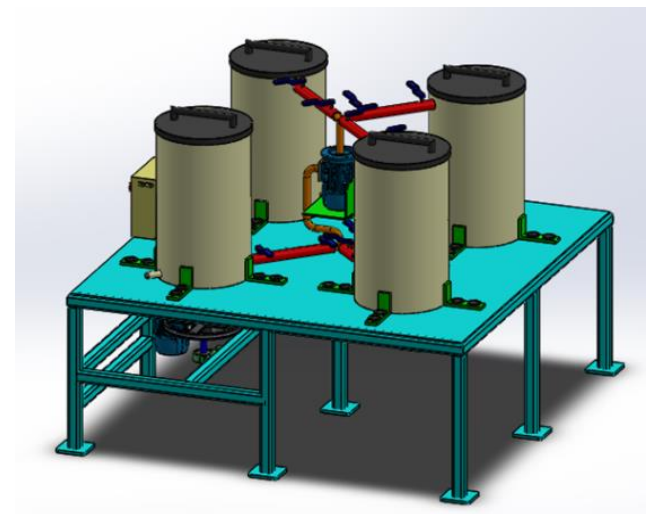

Gambar 4. Desain reaktor sistem batch untuk produksi biodiesel

\section{Kesimpulan}

Reaktor biodiesel sistem batch yang telah didesain memiliki kapasitas produksi 144 liter per-hari dengan spesifikasi sebagai berikut: terdiri dari 2 tabung volume masing-masing adalah 38,2 liter dengan material Stainless Steel dan 2 tabung volume masing-masing adalah 38,2 liter dengan material plastik HDPE daya motor adalah $260 \mathrm{~kW}$, diameter poros $20 \mathrm{~mm}$, panjang puli $134 \mathrm{~cm}$ menggunakan tipe A, proses pengadukan menggunakan bevel gear, dan jenis roda gigi yang digunakan adalah bahan S45C baja dicelup dingin dan temper.

\section{Ucapan terimakasih}

Ucapan terima kasih kami sampaikan kepada Kementrian Riset, Teknologi, dan Perguruan Tinggi yang telah membiayai penelitian ini dan juga kepada LPPM
Universitas Muhammadiyah Tasikmalaya yang telah mengarahkan, memonitor, dan megevaluasi penelitian ini.

\section{Referensi}

[1] Hambali, E., Mujdalipah, S., Tambuan, A. H., Pattiwiri, A. W., \& Hendroko, R. (2007). Teknologi Bioenergi. Jakarta: Agromedia.

[2] Hendrawati, T. Y., \& Ramadhan, A. I. (2018). Pemetaan Bahan Baku dan analisis Teknoekonomi Biodiesel dari Kelapa sawit. In Pengembangan Energi Baru Terbarukan (EBT) dan green Technology untuk Memandirian Bangsa (p. EBT-3). Jakarta: Fakultas Teknik Universitas Pancasila.

[3] Lubis, M. S. W. (2017). Ini 20 Perusahaan Pemasok Biodiesel ke Pertamina \&amp; AKR. Retrieved from http://industri.bisnis.com/read/20171 103/44/705707/ini-20-perusahaanpemasok-biodiesel-ke-pertamina-akr

[4] Riza. (2015). Spesifikasi Mutu B-20 di Idonesia dan Perbandingannya dengan spesifikasi Biodiesel, Minyak solar dan standard International. Jakarta: Balai Rekayasa Desain dan Sistem Teknologi-BPPT.

[5] Setiawati, E., Riset, F. E. B., Standardisasi, D., \& Banjarbaru, I. (n.d.). Sebagai alternatif bahan bakar mesin diesel (technology processing of biodiesel from used cooking oil by microfiltration and transesterification techniques as an alternative fuel of diesel engine) 1) 2). Retrieved from http://aesigit.multiply.com/journal/ite $\mathrm{m} / 1$

[6] Soelarso. (1997). Dasar-dasar perencanaan dan pemilihan elemen mesin, Pradya Pramita, Jakarta.

[7] Suharto. (2017). Bioteknologi dalam Bahan Bakar Nonfosil. Yogyakarta: Andi Yogyakarta.

[8] Triwahyuningsih, N., \& Adiprasetya, 
R. (2008). Pemanfaatan Energi

Biomassa sebagai Biofuel: Konsep

Sinergi dengan Ketahanan Pangan.

Yogyakarta.

[9] Ula, S., \& Kurniadi, W. (2017). Studi kelayakan produksi biodiesel dari minyak jelantah skala industri kecil. Al Jazari Journal of Mechanical Engineering (Vol. 2).

[10] Widodo. (2011). Analisis Kelayakan Usaha Pengolahan Minyak Jelantah (Waste Cooking Oil) Menjadi Biodiesel. Thesis (https:// repository.ipb.ac.id/handle/12345678 9/53191). 